\title{
USING OZONE LIDAR TO INVESTIGATE SOURCES OF HIGH OZONE CONCENTRATIONS IN THE WESTERN UNITED STATES
}

\author{
C. J. Senff ${ }^{1,2}$, A. O. Langford ${ }^{2}$, R. J. Alvarez $\mathrm{II}^{2}$, Wm. A. Brewer ${ }^{2}$, R. M. Banta ${ }^{2}$, R. D. \\ Marchbanks $^{1,2}$, S. P. Sandberg ${ }^{2}$, A. M. Weickmann ${ }^{1,2}$, J. S. Holloway ${ }^{1,2}$, E. J. Williams ${ }^{2}$ \\ ${ }^{1}$ CIRES, University of Colorado, Boulder, CO 80309, USA, *Email: christoph.senff@noaa.gov
}

${ }^{2}$ NOAA/ESRL/CSD, Boulder CO 80305, USA

\begin{abstract}
We have used NOAA's Tunable Optical Profiler for Aerosol and oZone (TOPAZ) ozone lidar to investigate the sources of high surface ozone concentrations in two different regions of the western United States (US): the Uintah Basin in northeast Utah and Clark County in southern Nevada, which includes the city of Las Vegas. The Uintah Basin is a booming oil and gas producing region that often suffers from very high wintertime ozone concentrations. Clark County experiences violations of the US ozone standard primarily in spring and early summer despite a lack of any major local pollution sources. TOPAZ lidar observations, in conjunction with surface in situ measurements and model results, provided strong evidence that the high wintertime ozone concentrations in the Uintah Basin are primarily driven by local emissions associated with oil and gas exploration, whereas the Clark County ozone exceedances are often caused by ozone-rich air that is transported from the lower stratosphere all the way down to the earth's surface.
\end{abstract}

\section{INTRODUCTION}

Atmospheric ozone concentrations in the US have generally decreased over the last two decades, especially in large cities, due to effective controls of ozone precursor emissions. However, the recent boom in oil and natural gas exploration in the US has led to an increase in regional ozone precursor emissions. These emissions are often poorly regulated and have been implicated in raising ambient ozone levels, in some cases well above the US ozone National Ambient Air Quality Standard (NAAQS), which is currently set at $75 \mathrm{ppbv}$ for 8 -hour average ozone. Exceedances of the ozone NAAQS have also been linked to stratosphere-to-troposphere transport (STT) of ozone and, to a lesser degree, transport of ozone from Asia. Observations and modeling studies have indicated that high-ozone layers of stratospheric or Asian origin can be transported from the free troposphere to the surface and cause a deterioration of air quality. This is especially true for the US Intermountain West, where elevated terrain and deep atmospheric boundary layers facilitate transport of free tropospheric air to the surface. These processes are bound to cause more ozone exceedances in the future as springtime ozone background concentrations over the western US are slowly increasing and the ozone NAAQS will likely be lowered to between 65 and 70 ppbv. This will effectively shrink the margin of ozone than can be added to the background before an exceedance occurs.

We deployed the TOPAZ ozone lidar, together with NOAA's High Resolution Doppler Lidar (HRDL), a large array of in situ instruments, and other remote sensors, at the Uintah Basin Wintertime Ozone Study (UBWOS) in January and February 2013 to investigate the sources of high surface ozone concentrations that had been observed during the winter months in the Uintah Basin. The main objective of the lidar deployment was to determine whether long-range transport of ozone, STT, or emissions from a nearby power plant could cause the high surface ozone levels, or if emissions from the local oil and gas extraction operations were the main source. Another goal was to characterize the vertical extent of the high ozone concentrations.

We also used TOPAZ, along with a smaller complement of in situ sensors, during the Las Vegas Ozone Study (LVOS) in May and June 2013 to investigate the causes for ozone NAAQS exceedances that occur in Clark County, Nevada during spring and early summer [1]. The primary objective was to assess the seasonal influence of STT and long-range transport from Asia on surface ozone concentrations. Secondary goals included the characterization of local photochemical production and regional transport of ozone from the Los Angeles Basin, and 
understanding the impacts of wildland fires on ozone levels in the Las Vegas area.

\section{METHODOLOGY}

The TOPAZ ozone lidar, deployed during both UBWOS and LVOS, is based on an all-solid-state transmitter and emits three tunable ultraviolet (UV) wavelengths between 285 and $300 \mathrm{~nm}$ [2]. Originally conceived as an airborne, nadirpointing instrument, TOPAZ was converted to an up-looking, truck-based system in early 2012 [3] (Fig. 1). A roof-mounted two-axis scanner permits

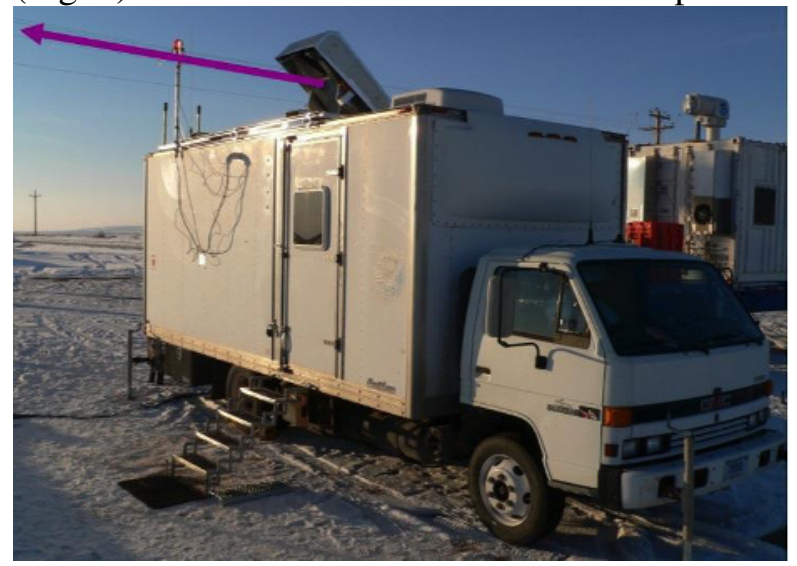

Figure 1: TOPAZ truck with roof-mounted scanner.

pointing of the laser beam at several elevation angles at a fixed but changeable azimuth angle. Zenith operation is achieved by moving the scanner mirror out of the laser beam path. A typical scan sequence consists of observations at elevation angles of 2, 6, 10, and 90 degrees. The ozone profiles from the various elevation angles are spliced together to create composite vertical profiles extending from $15 \mathrm{~m}$ up to about $3 \mathrm{~km}$ AGL (Fig. 2). The time resolution of the
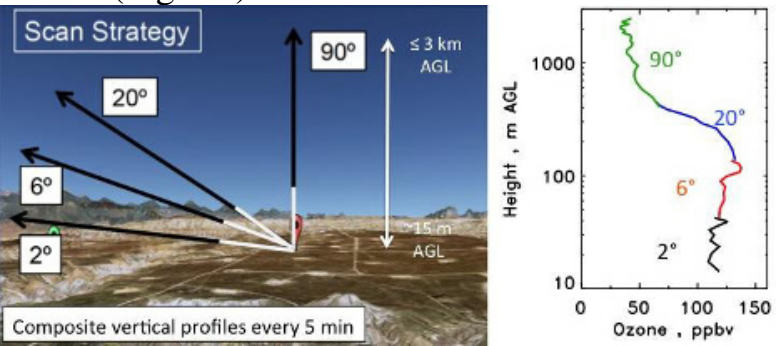

Figure 2: TOPAZ scan pattern (right) and composite vertical ozone profile (left).

composite ozone profiles is typically $5-15$ minutes and their effective vertical resolution increases with altitude from 3 to $90 \mathrm{~m}$. The TOPAZ lidar is unique because it allows profiling of ozone very close to the surface at high spatial resolutions, well below the minimum range of comparable zenith-looking lidars.

The HRDL Doppler wind lidar, deployed during the UBWOS campaign, provides profiles of horizontal wind speed and direction, horizontal and vertical turbulence, and boundary layer height typically at a time resolution of 20 minutes [4]. Wind profiles retrieved with HRDL in scanning mode are measured to within 5 meters of the surface and with 5-meter vertical resolution.

During LVOS, surface ozone and carbon monoxide $(\mathrm{CO})$ concentrations were determined at 1-min resolution using a commercial UVabsorbance monitor and a modified commercial vacuum UV-fluorescence monitor, respectively. A GPS-enabled weather station recorded 5-min averaged winds, temperature, and relative humidity from a 3-m mast. The LVOS measurement activities were guided by forecasts and analyses from the NOAA/ESRL/CSD FLEXPART particle dispersion model and the NOAA/NESDIS/CIMSS Real Time Air Quality Modeling System (RAQMS). Interpretation of the measurements was aided by support from the NOAA/ESRL/GFDL AM3 chemistry-climate model.

\section{RESULTS}

\subsection{UBWOS study}

The Uintah Basin in northeast Utah is about $120 \mathrm{x}$ 80 kilometers in size, almost completely surrounded by mountain ranges, and contains more than 10,000 active oil and gas wells (Fig. 3).

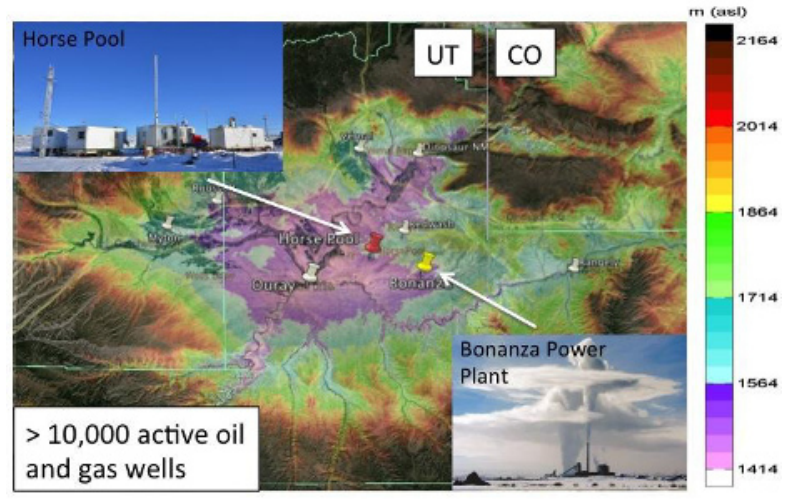

Figure 3: Map with the topography of the Uintah Basin in northeast Utah.

The TOPAZ and HRDL lidars, along with a comprehensive suite of chemistry and aerosol in situ sensors were situated at the Horse Pool site in the eastern part of the Basin. Normally, the 
ground in the Uintah Basin is snow covered throughout the winter and a persistent, shallow cold-pool layer of air forms in the Basin. A strong temperature inversion capping this cold-pool layer coupled with very light winds causes a buildup of pollutants in the Basin over several days, which can lead to very high surface ozone concentrations of up to $150 \mathrm{ppbv}$. These ozone episodes come to an end when high winds and strong mixing associated with passing storm systems dilute and flush out the high ozone concentrations. Figure 4 shows an ozone time-height cross section

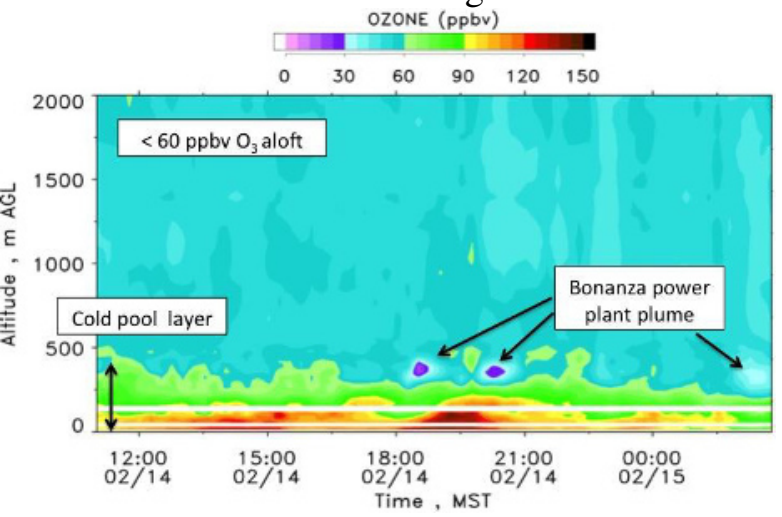

Figure 4: Ozone structure observed with the TOPAZ lidar on February 14-15, 2013.

observed with the TOPAZ lidar over a 16-hour period on February 14-15 2013. The ozone structure observed on that day was typical for all high ozone days encountered during the UBWOS study. The lidar observations show that the high ozone concentrations were confined to the coldpool layer, which was about $400 \mathrm{~m}$ deep. The plume from the nearby Bonanza power plant (Fig. 3) manifests itself in the lidar observations as lowozone patches (Fig. 4) because of titration of ambient ozone by power plant NOx. The power plant plume stayed above the temperature inversion at the top of the cold-pool layer and did not get mixed down to the surface. Therefore, the Bonanza power plant emissions were not part of the surface ozone precursor mix. Ozone concentrations above the cold-pool layer were below $60 \mathrm{ppbv}$ at all times, which is consistent with free-troposphere background ozone concentrations. Thus, the lidar observations showed no evidence of long-range transport of ozone aloft or STT that could have caused the high surface ozone levels.

\subsection{LVOS study}

During the LVOS study, the TOPAZ lidar and the ozone, $\mathrm{CO}$, and water vapor in situ instruments were located about $45 \mathrm{~km}$ west of Las Vegas on top of Angel Peak at about 2700 m MSL (Fig. 5).

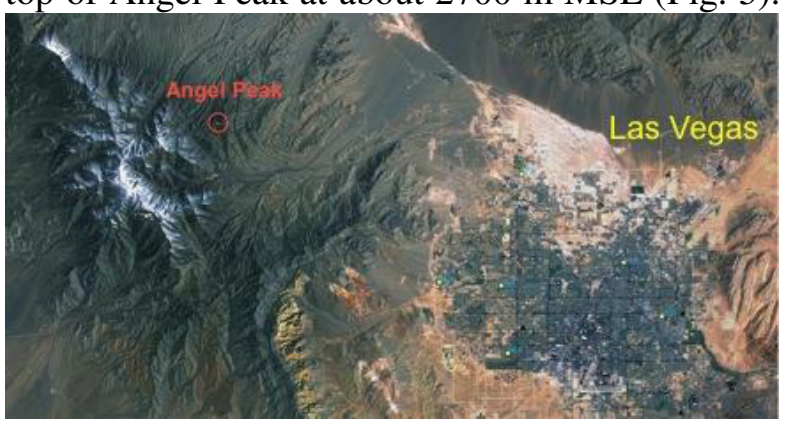

Figure 5: Map of LVOS study area.

TOPAZ collected approximately 200 hours of data on 26 days during May/June 2013. Fig. 6 depicts the ozone lidar and surface in situ observations on May 24-25. The lidar data show three high-ozone filaments sloping downward toward the surface, two of which reached the

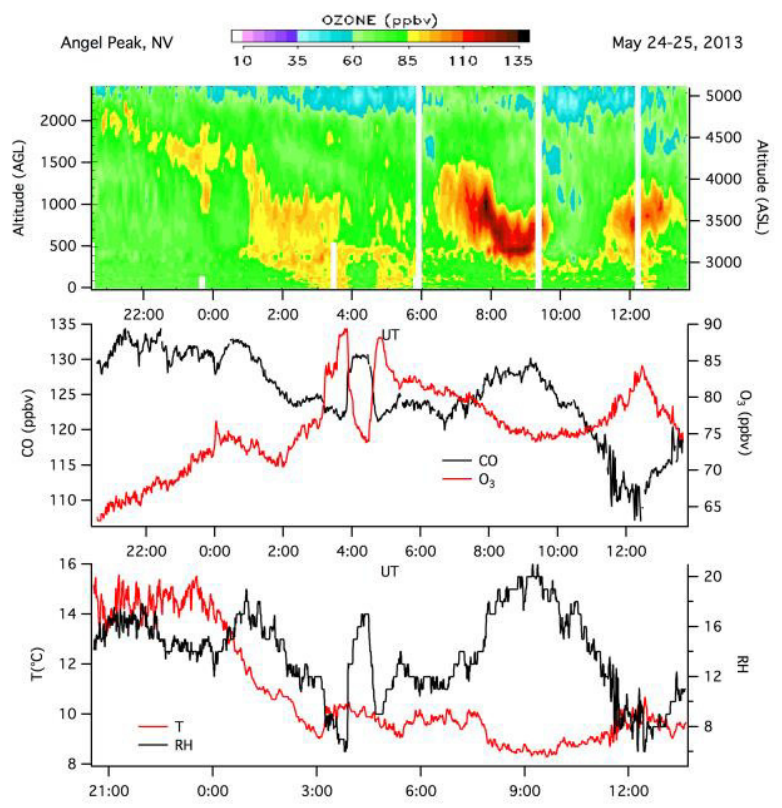

Figure 6: Vertical ozone distribution observed with TOPAZ on May 24-25, 2013 and coincident surface ozone, carbon monoxide, relative humidity, and air temperature measurements.

ground. At the same time, the in situ sensors show a simultaneous increase in surface ozone and a decrease in $\mathrm{CO}$ and relative humidity, indicating that these ozone filaments originated in the lower stratosphere. These measurements show the first ever example of a stratospheric intrusion being 
tracked continuously to the surface by lidar and then directly detected on the ground by in situ measurements. These observations were corroborated by FLEXPART back trajectory calculations and AM3 as well as RAQMS model analyses. Nocturnal drainage flows transported the high-ozone air into the Las Vegas valley, leading to exceedances of the ozone NAAQS on the following day. During LVOS, we observed two other cases where high-ozone air of stratospheric origin reached the surface at Angel Peak and subsequently caused violations of the ozone standard in Clark County. Contributions to elevated surface ozone from wildland fires and pollution plumes from the Los Angeles Basin were of secondary importance during the LVOS campaign and did not result in any ozone NAAQS exceedances.

\section{CONCLUSIONS}

TOPAZ lidar measurements from the UBWOS campaign revealed that neither STT, nor longrange transport of ozone, nor power plant emissions contributed in any significant way to the high wintertime surface ozone concentrations in the Uintah Basin. Our observations strongly support the conclusion, also reached by the other UBWOS investigators, that the local emissions associated with the oil and gas exploration are the primary driver of the high surface ozone levels in the Uintah Basin.

During LVOS, TOPAZ lidar observations, in conjunction with the collocated in situ measurements and supported by model results, provided compelling evidence that STT significantly increased surface ozone concentrations in the Las Vegas area during the late spring and early summer of 2013. Both measurements and model analyses suggest that ozone of stratospheric origin directly contributed to the exceedances of the ozone NAAQS in Clark County on three days in May and June 2013.

\section{ACKNOWLEDGEMENT}

We would like to acknowledge funding support from the NOAA Health of the Atmosphere and Climate Programs, the NASA Tropospheric Ozone Lidar Network, the Utah Department of Environmental Quality, the Western Energy Alliance, and the Clark County Department of Air Quality.

\section{REFERENCES}

[1] Langford, A. O., C. J. Senff, C. J., R. J. Alvarez II., J. Brioude, J., O. R. Cooper, J. S. Holloway, M. Y. Lin, R. D. Marchbanks, R. B. Pierce, S. P. Sandberg, A. M. Weickmann, E. J. Williams, 2014: An overview of the 2013 Las Vegas Ozone Study (LVOS): Impact of stratospheric intrusions and long-range transport on surface air quality, Atmospheric Environment (2014), doi: 10.1016/j.atmosenv.2014.08.040.

[2] Alvarez, R. J., et al, 2011: Development and application of a compact, tunable, solid-state airborne ozone lidar system for boundary layer profiling, J. Atmos. Ocean. Technol., doi: 10.1175/JTECH-D-10-05044.1

[3] Alvarez, R. J., Senff, C. J., A. M. Weickmann, S. P. Sandberg, A. O. Langford, R. D. Marchbanks, W. A. Brewer, and R. M. Hardesty, 2012: Reconfiguration of the NOAA TOPAZ Lidar for Ground-based Measurement of Ozone and Aerosol Backscatter, Proceedings of the $26^{\text {th }}$ International Laser Radar Conference, Porto Heli, Greece, 25-29 June 2012, pp. 249-252.

[4] Grund, C. J., R. M. Banta, J. L. George, J. N. Howell, M. J. Post, R. A. Richter, and A. M. Weickmann, 2000: High-resolution Doppler lidar for boundary layer and cloud research, J. Atmos. Ocean. Technol., 18, 376-393. 